\title{
Redox-dependent thiol modifications: implications for the release of extracellular vesicles
}

\author{
Birke J. Benedikter ${ }^{1,2}$ (D) Antje R. Weseler ${ }^{3}$ D $\cdot$ Emiel F. M. Wouters $^{2} \cdot$ Paul H. M. Savelkoul $^{1,4} \cdot$ Gernot G. U. Rohde $^{5}$. \\ Frank R. M. Stassen ${ }^{1}$
}

Received: 11 January 2018 / Revised: 9 March 2018 / Accepted: 22 March 2018 / Published online: 28 March 2018

(c) The Author(s) 2018

\begin{abstract}
Extracellular vesicles (EVs), including microvesicles and exosomes, are emerging as important regulators of homeostasis and pathophysiology. During pro-inflammatory and pro-oxidant conditions, EV release is induced. As EVs released under such conditions often exert pro-inflammatory and procoagulant effects, they may actively promote the pathogenesis of chronic diseases. There is evidence that thiol group-containing antioxidants can prevent EV induction by pro-inflammatory and oxidative stimuli, likely by protecting protein thiols of the EV-secreting cells from oxidation. As the redox state of protein thiols greatly impacts three-dimensional protein structure and, consequently, function, redox modifications of protein thiols may directly modulate EV release in response to changes in the cell's redox environment. In this review article, we discuss targets of redox-dependent thiol modifications that are known or expected to be involved in the regulation of EV release, namely redox-sensitive calcium channels, $N$-ethylmaleimide sensitive factor, protein disulfide isomerase, phospholipid flippases, actin filaments, calpains and cell surface-exposed thiols. Thiol protection is proposed as a strategy for preventing detrimental changes in EV signaling in response to inflammation and oxidative stress. Identification of the thiol-containing proteins that modulate EV release in pro-oxidant environments could provide a rationale for broad application of thiol group-containing antioxidants in chronic inflammatory diseases.
\end{abstract}

Keywords Exosomes $\cdot$ Microvesicles $\cdot$ Sulfhydryl groups $\cdot$ Redox environment $\cdot$ Chronic inflammation $\cdot N$-acetyl-Lcysteine

Frank R. M. Stassen

f.stassen@maastrichtuniversity.nl

1 Department of Medical Microbiology, NUTRIM School of Nutrition and Translational Research in Metabolism, Maastricht University Medical Center, PO Box 5800, 6202 AZ Maastricht, The Netherlands

2 Department of Respiratory Medicine, NUTRIM School of Nutrition and Translational Research in Metabolism, Maastricht University Medical Center, PO Box 5800, 6202 AZ Maastricht, The Netherlands

3 Department of Pharmacology and Toxicology, NUTRIM School of Nutrition and Translational Research in Metabolism, Maastricht University, PO Box 616, 6200 MD Maastricht, The Netherlands

4 Department of Medical Microbiology and Infection Control, VU University Medical Center, P.O. Box 7057, 1007 MB Amsterdam, The Netherlands

5 Medical Clinic I, Department of Respiratory Medicine, Goethe University Hospital, Frankfurt/Main, Germany

$\begin{array}{ll}\text { Abbreviations } \\ \text { AFF-1 } & \text { Anchor cell fusion failure 1 } \\ \text { AnxV } & \text { Annexin V } \\ \text { ATP } & \text { Adenosine triphosphate } \\ \text { CSE } & \text { Cigarette smoke extract } \\ \text { DTNB } & \text { 5,5-Dithio-bis-(2-nitrobenzoic acid) } \\ \text { EFF-1 } & \text { Epithelial fusion failure 1 } \\ \text { ER } & \text { Endoplasmic reticulum } \\ \text { ESCRT } & \text { Endosomal sorting complex required for } \\ & \text { transport } \\ \text { EV } & \text { Extracellular vesicle } \\ \text { GAPDH } & \text { Glyceraldehyde 3-phosphate dehydrogenase } \\ \text { GSH } & \text { Glutathione } \\ \text { HCAEC } & \text { Human coronary artery endothelial cells } \\ \text { HNE } & \text { 4-Hydroxy-2-nonenal } \\ \text { ILV } & \text { Intraluminal vesicle } \\ \text { LPS } & \text { Lipopolysaccharide } \\ \text { MPG } & N \text {-(2-Mercaptopropionyl)glycine } \\ \text { MVE } & \text { Multivesicular endosome } \\ \text { NAC } & N \text {-acetyl-L-cysteine }\end{array}$




$\begin{array}{ll}\text { NACA } & N \text {-acetyl-L-cysteine amide } \\ \text { NEM } & N \text {-ethylmaleimide } \\ \text { NSF } & N \text {-ethylmaleimide sensitive factor } \\ \text { PDI } & \text { Protein disulfide isomerase } \\ \text { PE } & \text { Phosphatidylethanolamine } \\ \text { PS } & \text { Phosphatidylserine } \\ \text { RCS } & \text { Reactive carbonyl species } \\ \text { ROS } & \text { Reactive oxygen species } \\ \text { RPE } & \text { Retinal pigment epithelial cells } \\ \text { PRDX1 } & \text { Peroxiredoxin 1 } \\ \text { RyR } & \text { Ryanodine receptor } \\ \text { SERCA } & \text { Sarco/endoplasmic reticulum Ca }{ }^{2+} \text {-ATPase } \\ \text { SNAP } & \text { Soluble NSF attachment protein } \\ \text { SNARE } & \text { SNAP receptor } \\ \text { TEM } & \text { Transmission electron microscopy } \\ \text { TF } & \text { Tissue factor } \\ \text { TNF- } \alpha & \text { Tumor necrosis factor } \alpha \\ \text { TRPA1 } & \text { Transient receptor potential A1 } \\ \text { t-SNARE } & \text { Target membrane-associated SNARE } \\ \text { TRPS } & \text { Tunable resistive pulse sensing } \\ \text { VAMP7 } & \text { Vesicle-associated membrane protein 7 } \\ \text { v-SNARE } & \text { Vesicle-associated SNARE }\end{array}$

\section{Extracellular vesicles}

Extracellular vesicles (EVs) are small membrane-surrounded vesicles that are secreted by virtually all cell types and that have been detected in various body fluids including plasma [1], urine [2] and bronchoalveolar lavage fluid [3]. These EVs carry a complex cargo composed of proteins, nucleotides and lipids, among others [4]. They can exert multiple biological effects, either by interacting with or being taken up by target cells, or in the extracellular space [5]. As EVs are released under physiological and stress conditions, they have been attributed various functions in homeostasis as well as pathology [5].

\section{EV biogenesis and uptake}

In recent years, it has become clear that EVs are a heterogeneous population of membrane-delimited structures that emerge from distinct biogenetic pathways, and that have diverse biophysical and biochemical properties [6, 7]. This review focuses on two major EV types, exosomes and microvesicles, whose properties are summarized in Table 1. Several recent review articles provide a detailed overview of the current knowledge on EV biogenesis [8-10] and uptake $[11,12]$. Therefore, these processes will be described only briefly and non-comprehensively, to provide the necessary context for later sections of this article. Exosome biogenesis takes place in late endosomes, which transform into multivesicular bodies (MVBs) by inward budding of their membrane to form small intraluminal vesicles (ILVs). These MVBs can then fuse with the plasma membrane and release their ILVs to the extracellular space as exosomes. In contrast to exosomes, microvesicles are released from the cell by outward budding of the plasma membrane followed by membrane fission. The membrane rearrangements that occur during exosome and microvesicle biogenesis are regulated by energy-dependent enzymes, including Rab GTPases and the endosomal sorting complex required for transport (ESCRT). EV uptake by target cells appears to occur most commonly by endocytosis or phagocytosis followed by membrane fusion within the endocytic compartment. An alternative pathway is direct membrane fusion at the cell surface.

\section{Pathophysiological relevance of redox-mediated EV signaling}

EVs are actively involved in the pathophysiology of conditions that are associated with local or systemic inflammation and oxidative stress, such as unhealthy aging (also termed 'inflammaging'), cancer, cardiovascular disease (CVD) and chronic lung diseases [13-16]. Several in vitro studies have shown that exposure of EV-secreting cells to pro-inflammatory or pro-oxidant conditions causes pathological changes in EV signaling $[17,18]$. Moreover, chronic inflammatory

Table 1 Summary of the differential properties of exosomes and microvesicles. ESCRT, endosomal sorting complex required for transport; MVB, multivesicular body

\begin{tabular}{llc}
\hline & Exosomes & Microvesicles \\
\hline Alternative names & Extracellular vesicles & $\begin{array}{c}\text { Extracellular vesicles, microparticles, shed- } \\
\text { ding vesicles, ectosomes } \\
\text { Size }\end{array}$ \\
Biogenesis & $50-150 \mathrm{~nm}$ & $100-1000 \mathrm{~nm}$ \\
& As ILVs in MVBs, followed by extracellular release by fusion of the & Direct shedding from the plasma membrane \\
Characteristic proteins & Tetraspanins (e.g., CD63, CD81, CD9), ESCRT components (ALIX, & Integrins, selectins \\
& TSG101) &
\end{tabular}


diseases are associated with oxidative stress as well as elevated $\mathrm{EV}$ concentrations and altered $\mathrm{EV}$ composition, both of which can contribute to adverse biological effects of EVs $[15,19,20]$. Pharmacological modulation of EV formation may, therefore, be a promising treatment strategy for multiple chronic inflammatory conditions. However, most known targets for inhibiting EV release, including neutral sphingomyelinase 2 and the GTPase Rab27a [21, 22], are required for vital cellular processes such as lipid biosynthesis and intracellular membrane trafficking [23, 24]. Therefore, currently known strategies for EV inhibition are likely associated with off-target effects, hampering their application for the therapeutic modulation of EV signaling in vivo. An improved understanding of the mechanisms that modulate EV release under conditions of chronic inflammation and oxidative stress could allow identifying pharmacological compounds that only prevent pathological changes in EV signaling, but do not interfere with the physiological functions of EVs. Protein thiols can undergo reversible redox modifications. Thereby, they can act as switches in cellular redox signaling, and determine the cell's response to changes in its redox environment $[25,26]$. In this review article, we discuss how thiol modifications may be involved in EV formation and propose thiol protection as a novel strategy for preventing pathological changes in EV signaling.

\section{Redox regulation of protein thiols}

This section provides general background information on how redox modifications of protein thiols affect protein function and, consequently, cellular functions. It aims to familiarize the reader with important principles and terminology in the field of redox-dependent thiol modifications before we discuss "Modulation of EV signaling by thiol modifications" in the next section.

Thiol groups in proteins are contributed by the amino acid cysteine. Most commonly, protein thiols exist either in a free, reduced form (Cys-SH), or oxidized to a disulfide with another thiol group of the same or another protein (Cys-S-S-Cys) [27]. During protein biosynthesis, disulfide bonds are introduced in a highly regulated manner. They are essential for correct three-dimensional protein structure and, consequently, for protein function. To assure correct protein folding, the position of cysteine residues within proteins is highly conserved [28]. Reduced thiols are nucleophilic and susceptible to electrophilic attacks because of their electron-rich sulfur atom [25]. Certain protein microenvironments polarize the $\mathrm{S}-\mathrm{H}$ bond and thereby lower the acid dissociation constant $\left(\mathrm{p} K_{\mathrm{a}}\right)$ of thiol groups. This favors their deprotonation (i.e., the dissociation of $\mathrm{H}^{+}$), resulting in the formation of even more reactive thiolate anions $\left(\mathrm{Cys}-\mathrm{S}^{-}\right)$
[27]. This often occurs at active site cysteines, making them especially susceptible for redox modifications [29].

Electrophilic compounds that are prone to react with thiolates or thiols include reactive oxygen species (ROS), which can lead to the formation of ectopic disulfide bonds, reactive nitrogen species (RNS) which lead to S-nitrosylation or S-nitration (Cys-S-NO) and reactive carbonyl species (RCS) which result in adduct formation (Cys-S-R) [26] (illustrated in Fig. 1). ROS, RNS and RCS are present in environmental exposures, including cigarette smoke and vehicle emissions [30-32] and are also formed endogenously, for instance, during inflammation and lipid peroxidation [33-35]. Reaction of such oxidative stimuli with protein thiols can strongly affect protein conformation and functionality and cysteine-rich proteins often underlie redox regulation, especially those containing unpaired cysteines with free thiol groups [27]. The cell has a powerful antioxidant system at its disposal, which consists of glutathione and various antioxidant enzymes [36]. Up to moderate oxidant levels, this system is able to control and reverse thiol modifications by ROS and RCS, thereby allowing oxidative thiol modifications to act as transient and specific cell signaling events $[36,37]$. Studies that investigate the regulation of protein function by redox sensitive thiols often apply electrophiles that covalently modify thiols, trapping them either transiently or irreversibly in an oxidized state [29]. Here, we will refer to these chemicals as thiol scavengers.

In the following sections, we discuss how thiol modifications may be involved in EV formation and how thiol protection may be used to prevent pathological changes in EV signaling.

\section{Modulation of EV signaling by thiol modifications}

\section{Modulation of EV release}

Intriguingly, it was reported as early as 1961 that treatment of various cells with thiol-reactive compounds induces blebbing of the plasma membrane [38]. In 1979, Scott and Maercklein found that these blebs were released into the cell culture media as $100 \mathrm{~nm}$ - to $10 \mu \mathrm{m}$-sized vesicles and could be isolated by centrifugation at $30,000 \times g$ [39]. The phenomenon was universal for cultured cells from different species and tissues, including fibroblasts, monocytes and macrophages and could be induced by a wide panel of RCS, including formaldehyde, $N$-ethyl-maleimide (NEM) and acrolein [39]. More recently, we and others have confirmed that treatment of various cell types with RCS or ROS enhances the release of EVs (for details, see Table 2) [40-43]. A number of studies have shown that both ROS-dependent and RCS-dependent EV induction are preventable by thiol-based 


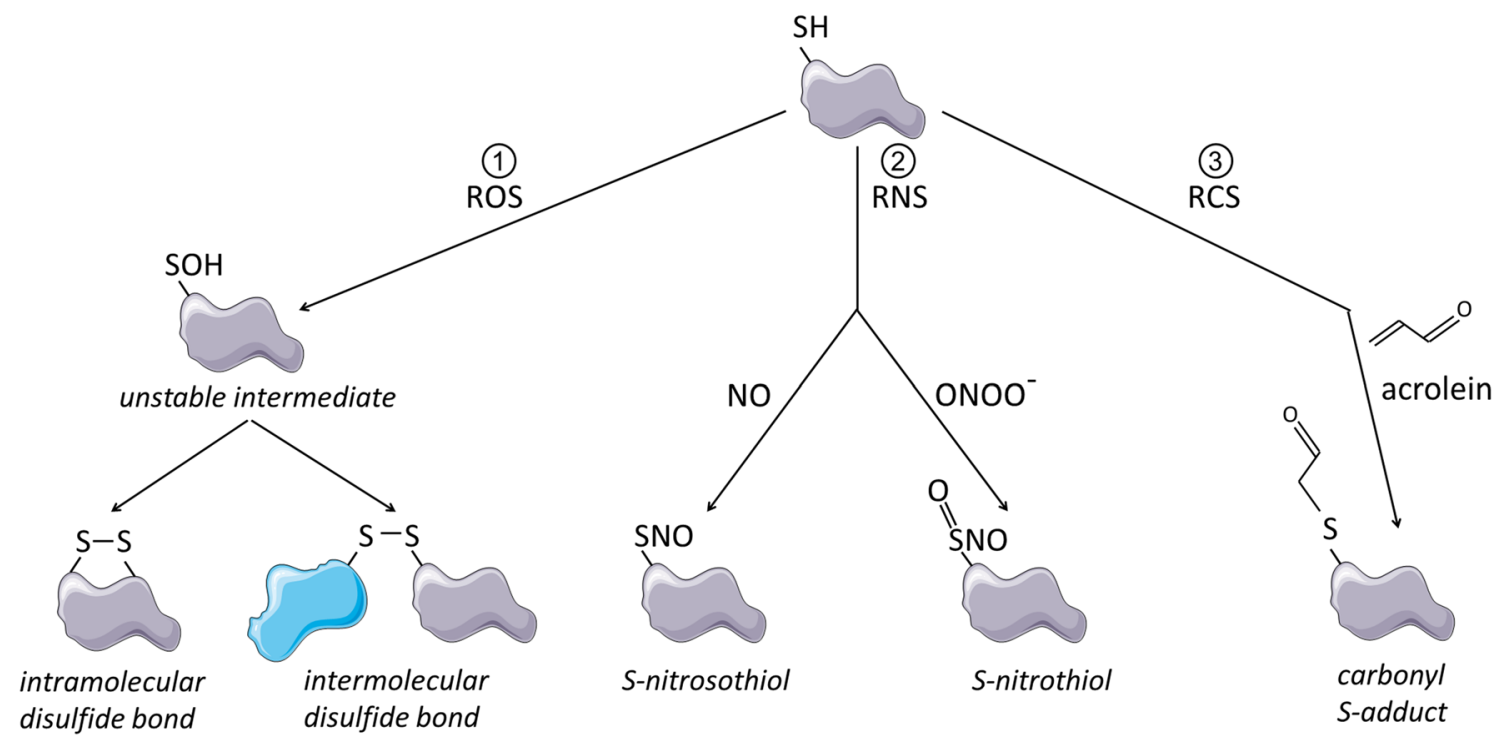

Fig. 1 Schematic representation of thiol modifications by ROS, RNS and RCS. (1) Thiol oxidation by ROS leads to formation of an unstable cysteine sulfenic acid intermediate. This unstable intermediate can react with other thiol groups within the same or another molecule, which leads to formation of intramolecular or intermolecular disulfide bonds. (2) Thiol modification by RNS such as nitric oxide (NO) or peroxynitrite $\left(\mathrm{ONOO}^{-}\right)$leads to S-nitrosylation or S-nitration. (3) Thiol modification by RCS causes formation of relatively large and bulky carbonyl S-adducts as illustrated here for acrolein. This figure was created using Servier Medical Art antioxidants such as NAC [41-43], suggesting that thiolreactivity is causally linked to EV induction. Yet, while Vatsyayan et al. proposed that RCS-induced EV release is mediated by secondary ROS generation, we found that only RCS, but not the ROS hydrogen peroxide, elicit increased EV release [40, 41]. Vatsyayan et al. and the studies that showed ROS-induced EV release detected EVs by direct flow cytometry for microvesicles (detection limit $300 \mathrm{~nm}$ ) $[40,42,43]$, whereas we used a combination of tunable resistive pulse sensing and bead-based flow cytometry to detect small EVs (85-250 nm) expressing exosome marker proteins [41]. Therefore, thiol modifications by RCS and ROS may differentially affect the release of microvesicles and exosomes. Moreover, it may depend on the cell type and its repertoire of proteins with redox sensitive thiols whether a certain stimulus does or does not trigger EV release. For instance, in the study by Vatsyayan et al., cell exposure to the RCS 4-hydroxy-2-nonenal enhanced the release of EVs by endothelial cells and fibroblasts, but not by monocytes [40].

In some studies, ROS or RCS-induced microvesicle production was associated with a considerable amount of apoptotic cell death $[23,48]$, suggesting that microvesicle shedding in the response to thiol-reactive compounds may be due to cytotoxicity rather than being directly mediated by thiol modifications. However, we have found that the thiol scavengers 5,5-dithio-bis-(2-nitrobenzoic acid) DTNB and bacitracin induce EVs without affecting cell viability [29] and other mechanisms have been implied in ROS and RCSdependent EV induction, as will be discussed later. While the effect of RNS on EV release is less well studied than that of ROS and RCS, there is evidence that nitric oxide (NO) negatively regulates EV release [44, 45]. Table 2 gives an overview of the experimental evidence for modulation of $\mathrm{EV}$ release by thiol-reactive compounds.

\section{Modulation of EV cargo and functions}

Functional implications of EVs released under oxidative stress conditions have been described in detail elsewhere $[18,46]$. Therefore, we will only discuss those studies that explicitly investigated EV functions related to oxidative thiol modifications. Szabó-Taylor et al. have exposed monocytes to pro-inflammatory conditions associated with oxidative stress and assessed the expression of the thiol-dependent redox enzyme peroxiredoxin 1 on the cells and their EVs [47]. While exofacial peroxiredoxin 1 was readily detectable on both, secreting cells and EVs, the over oxidized and enzymatically inactive form was exclusively enriched on the EVs [47]. This suggests that cells may release membrane proteins with oxidized thiol groups on EVs to maintain a reduced membrane status in oxidative environments. Similarly, the thiol groups of the cytosolic enzyme glyceraldehyde 3-phosphate dehydrogenase (GAPDH) become oxidized during red blood cell storage and the oxidized form of GAPDH is then released in an EV-associated manner [48]. This implies that intraluminal proteins with oxidized thiols may also be released in EVs as a protective mechanism. 


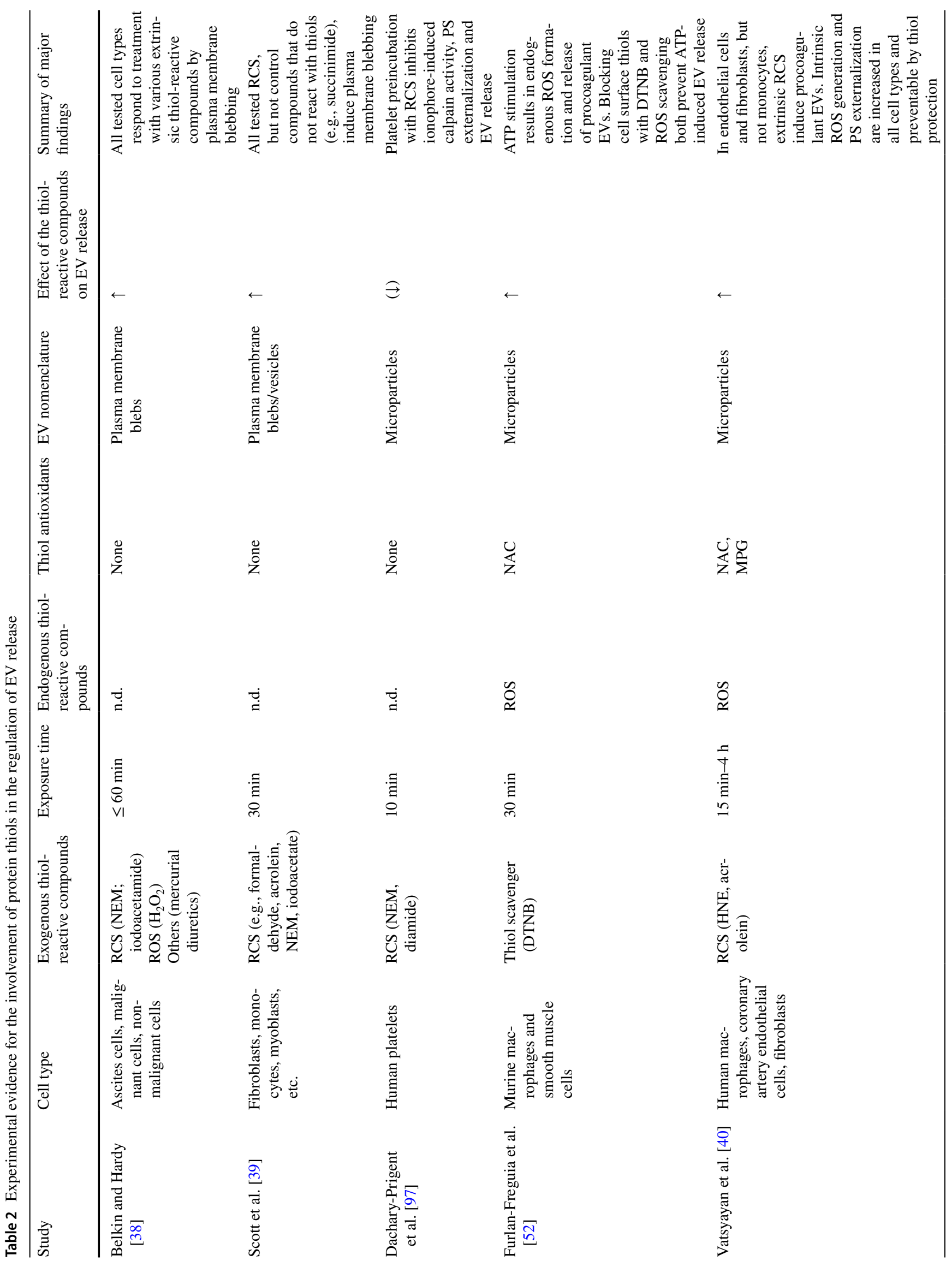




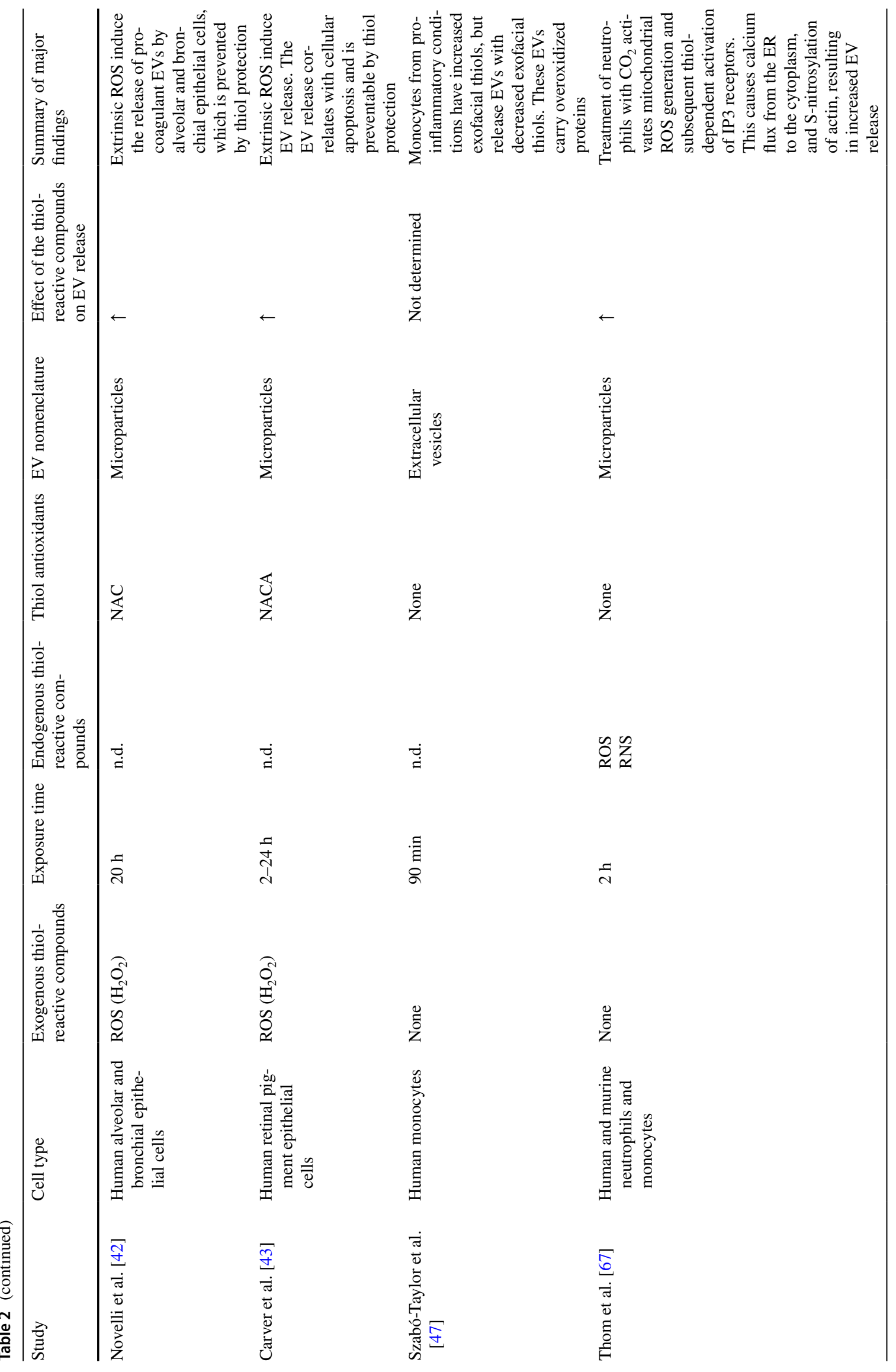




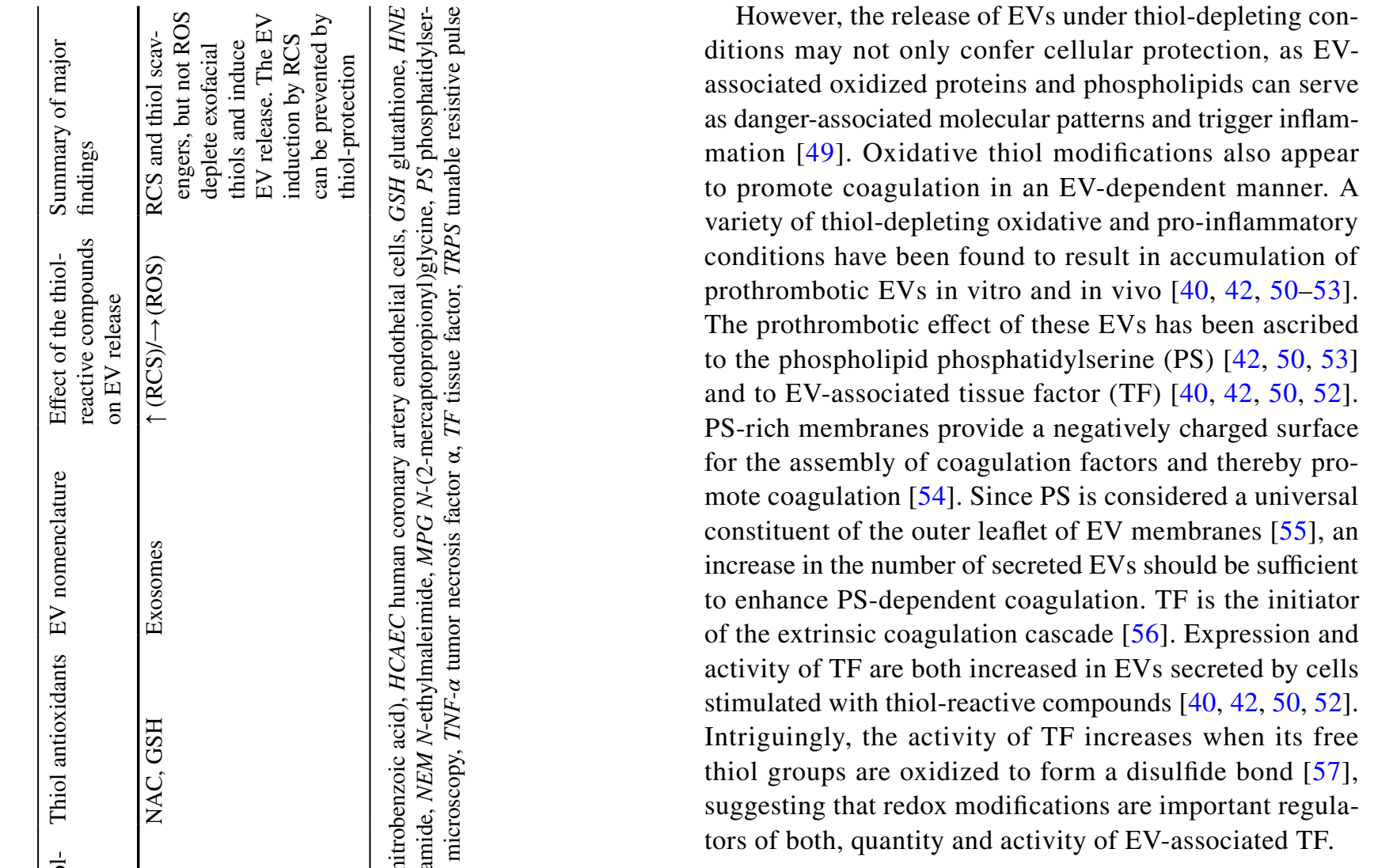

\section{Summary}

Cell exposure to thiol-reactive compounds, particularly RCS and ROS, results in plasma membrane blebbing and increased release of EVs. EVs released in response to thiol modifications protect the secreting cell from oxidative damage, but also promote potentially harmful processes such as inflammation and coagulation.

\section{Molecular targets of thiol modifications that regulate EV release or EV uptake}

Although thiol modifications modulate the release and biological functions of EVs, relatively little is known about the thiol-bearing proteins that mediate these changes. In this section, various thiol-dependent mechanisms are presented that regulate either membrane fusion or blebbing and that are known or hypothesized to modulate EV release. These mechanisms are summarized in Table 3 and visualized in Fig. 2. Additionally, three recent publications are discussed in detail, which specifically imply modifications of cell surface-exposed thiols in EV release [41, $47,52]$. 


\section{Redox sensitive calcium channels}

Cytoplasmic calcium influx is a major inducer of both, microvesicle and exosome release, as it promotes membrane blebbing as well as fusion of MVBs with the plasma membrane $[58,59]$. Intriguingly, several calcium channels bear redox-sensitive thiol groups and become activated upon their oxidation [60-64] (Fig. 2a; for details of the different calcium channels see Table 3). The nociceptor transient receptor potential ankyrin subtype 1 (TRPA1) is among the best studied calcium channels whose activity is modulated by thiol modifications [65]. Expressed by sensory neurons and other sensory cells, including epithelial cells [65], TRPA1 becomes activated upon covalent thiol oxidation by RCS or ROS $[61,66]$. While a causal link between TRPA1 activation and induction of EV release has to our knowledge not been investigated, oxidative stimuli such as cigarette smoke and acrolein cause TRPA1 activation [63] and also enhance EV release [41]. Direct evidence that thioldependent calcium flux to the cytoplasm is associated with increased EV release stems from a study by Thom et al. The authors have shown that, ROS-dependent thiol oxidation of inositol-1,3,5-triphosphate (IP3) receptors triggers calcium flux from the endoplasmic reticulum to the cytoplasm and, consequently, EV release [67]. However, it should be noted that some calcium channels are inhibited, rather than activated by oxidative modification of their thiols [60]. Therefore, it may depend on the types of calcium channels expressed by a cell whether cytoplasmic calcium influx and, consequently, EV release is promoted or inhibited by cell exposure to thiol-reactive species.

Additionally to the direct effects of thiol modifications on EV release, the coming sections will also address how cytoplasmic calcium concentrations influence EV release.

\section{SNAREs and NSF}

Soluble $\mathrm{N}$-ethylmaleimide sensitive factor attachment protein receptors (SNAREs) mediate various intracellular membrane fusion events and are also involved in EV release [68-70]. In the presence of cytoplasmic calcium, e.g., upon activation of thiol-regulated calcium channels, vesicle-associated (v)-SNAREs and target membraneassociated ( $t$ )-SNAREs form a highly stable complex that can force two membranes together, resulting in membrane fusion (Fig. 2b) [71]. After SNARE-mediated fusion, the ATPase $N$-ethylmaleimide-sensitive factor (NSF) can translate the energy from ATP hydrolysis into a large conformational change that mechanically separates v-SNAREs and t-SNAREs, making them available for further membrane fusion events [71] (Fig. 2c). Importantly, activity of NSF depends on reduced thiols and can be inhibited by the thiol-reactive carbonyl $N$-ethyl-maleimide (NEM)
[72]. SNAREs as well as NSF have been implicated in the fusion of MVBs with the plasma membrane, resulting in exosome release $[69,73,74]$. Taken together, under oxidative conditions, thiol-dependent calcium influx is expected to cause SNARE-dependent exosome release. Yet, oxidation of the free thiol group of NSF may prevent recovery of the SNARE proteins for subsequent membrane fusion events.

\section{The protein disulfide isomerase family and thiol-rich fusion proteins}

The protein disulfide isomerase (PDI) family is a family of proteins with thiol-dependent oxidoreductase activity. The prototype family member PDI is expressed abundantly in most tissues and has two thioredoxin-like active sites (-CysXX-Cys-) [75]. Both active sites contain two cysteine residues, which catalyze various redox reactions, such as reduction of disulfide bonds, isomerization of disulfide bonds and oxidation of free thiols, by forming intermolecular disulfides with a substrate protein [76]. The redox state of PDI, and thus whether it is prone to catalyze oxidations or reductions, is controlled by other redox enzymes and by glutathione [75]. While most PDI is sorted to the endoplasmic reticulum (ER), significant amounts of PDI have also been detected associated with the plasma membrane, with the redox sites exposed on the cell surface [77], and secreted in an EVassociated form [52, 78, 79]. Importantly, PDI activity has been shown to be crucially involved in ATP-induced EV release by murine myeloid cells [52].

Several studies have implicated PDI family members as regulators of membrane fusion, making it conceivable that EV release and/or uptake can be mediated by PDI-dependent membrane rearrangements. For instance, sperm-egg fusion can be prevented by thiol scavengers and depends on expression of the PDI family member Erp57 on the sperm cell membrane and of the tetraspanins CD81 and CD9 on the egg cell membrane [80-82]. Notably, exosomal membranes are commonly associated with both tetraspanins and PDI, making it tempting to speculate that PDI may be involved in the fusion of tetraspanin-enriched membranes during EV biogenesis or uptake. Next to gamete fusion, the PDI family is also involved in the cell entry of several enveloped viruses, including retroviruses, whose biogenesis and cellular uptake bear striking resemblances to those of exosomes $[83,84]$. PDI-catalyzed reduction of disulfide bonds in viral fusion proteins induces conformational changes which mediate fusion of the viral envelope with the host cell membrane $[85,86]$. PDI may similarly regulate EV uptake by catalyzing thiol-disulfide exchange reactions in EV-borne fusion proteins. For instance, the fusion proteins syncytin-1 and syncytin-2 have been identified on EVs and proposed to mediate EV uptake by target cells [87]. The fusogenic 


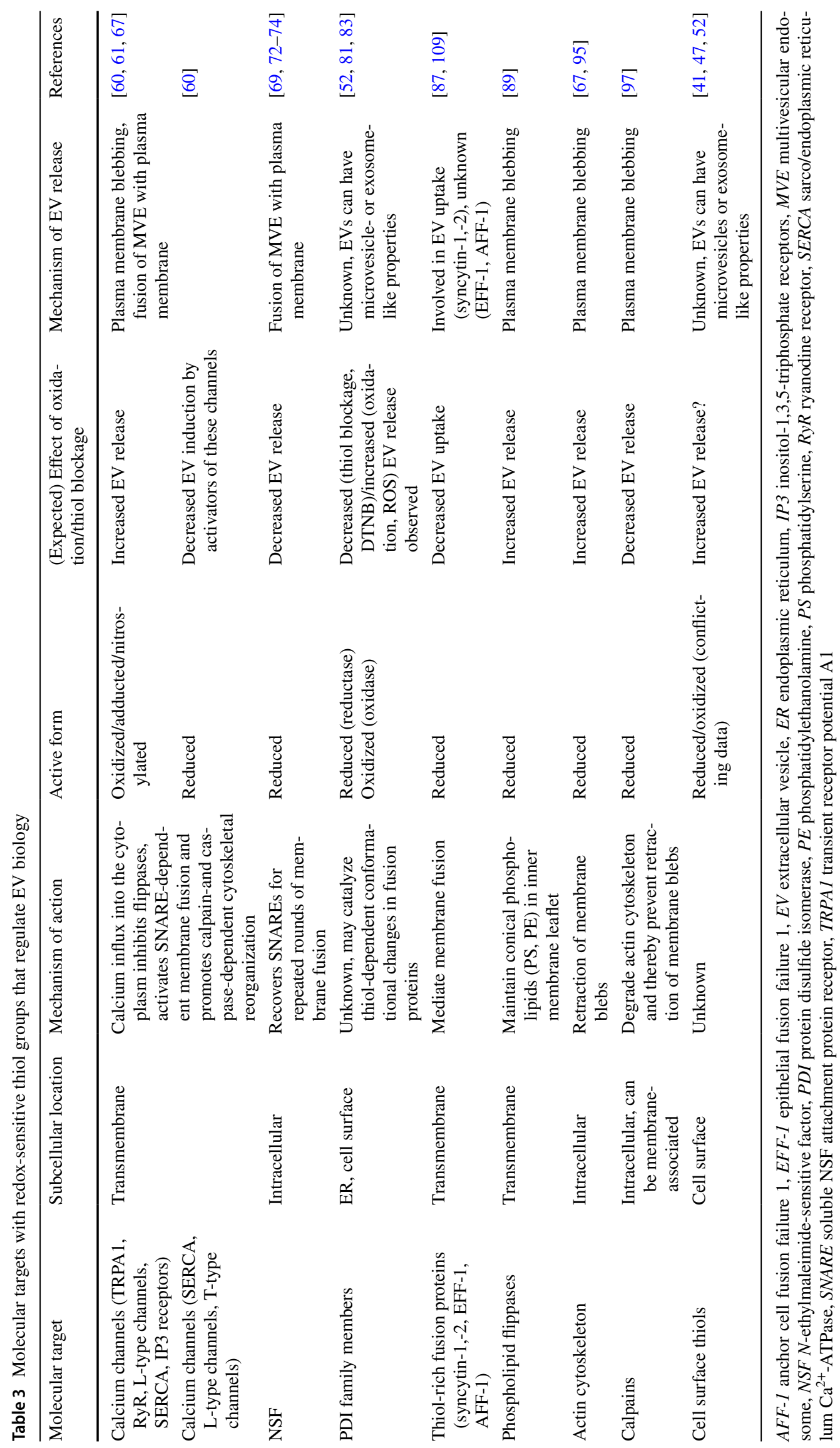


A
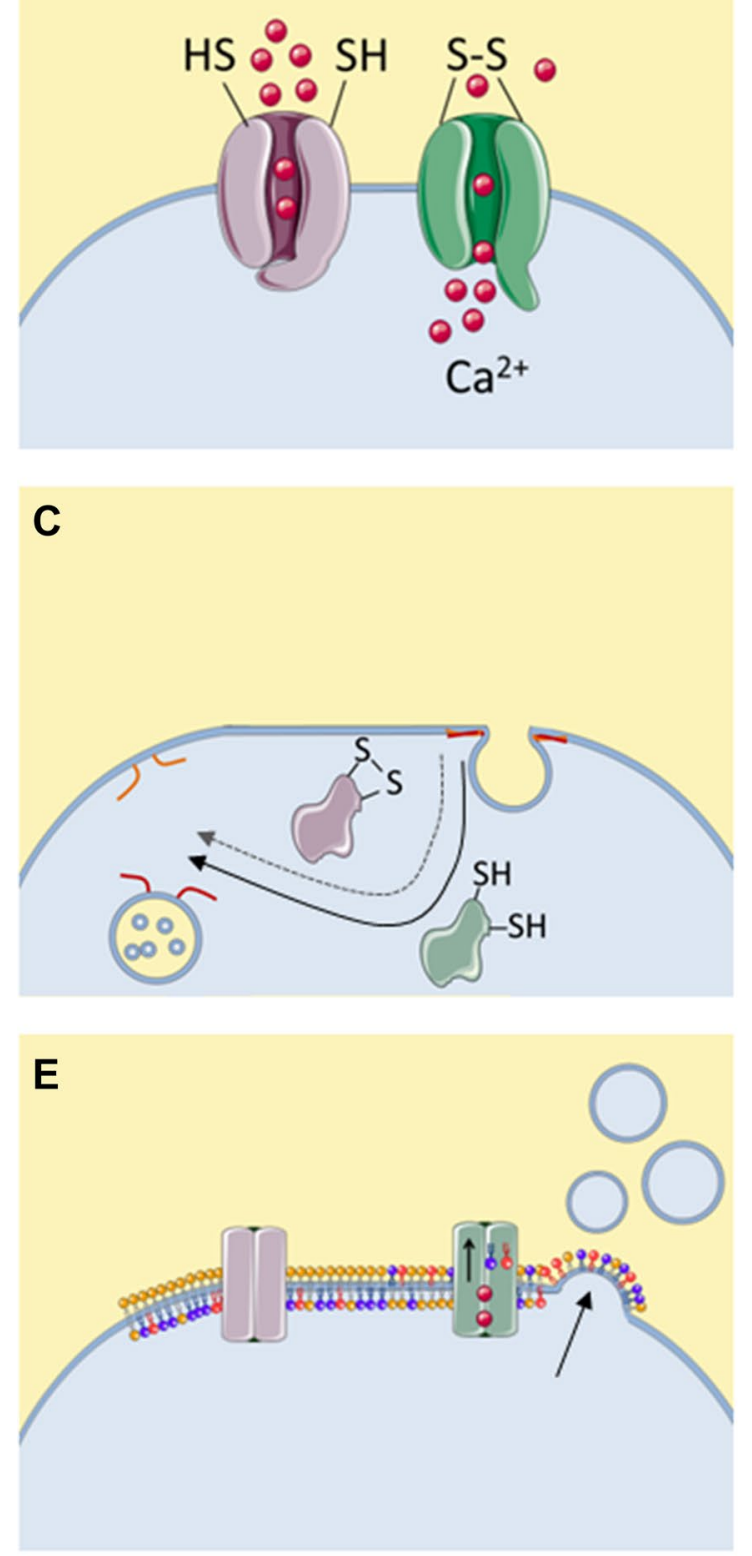

B
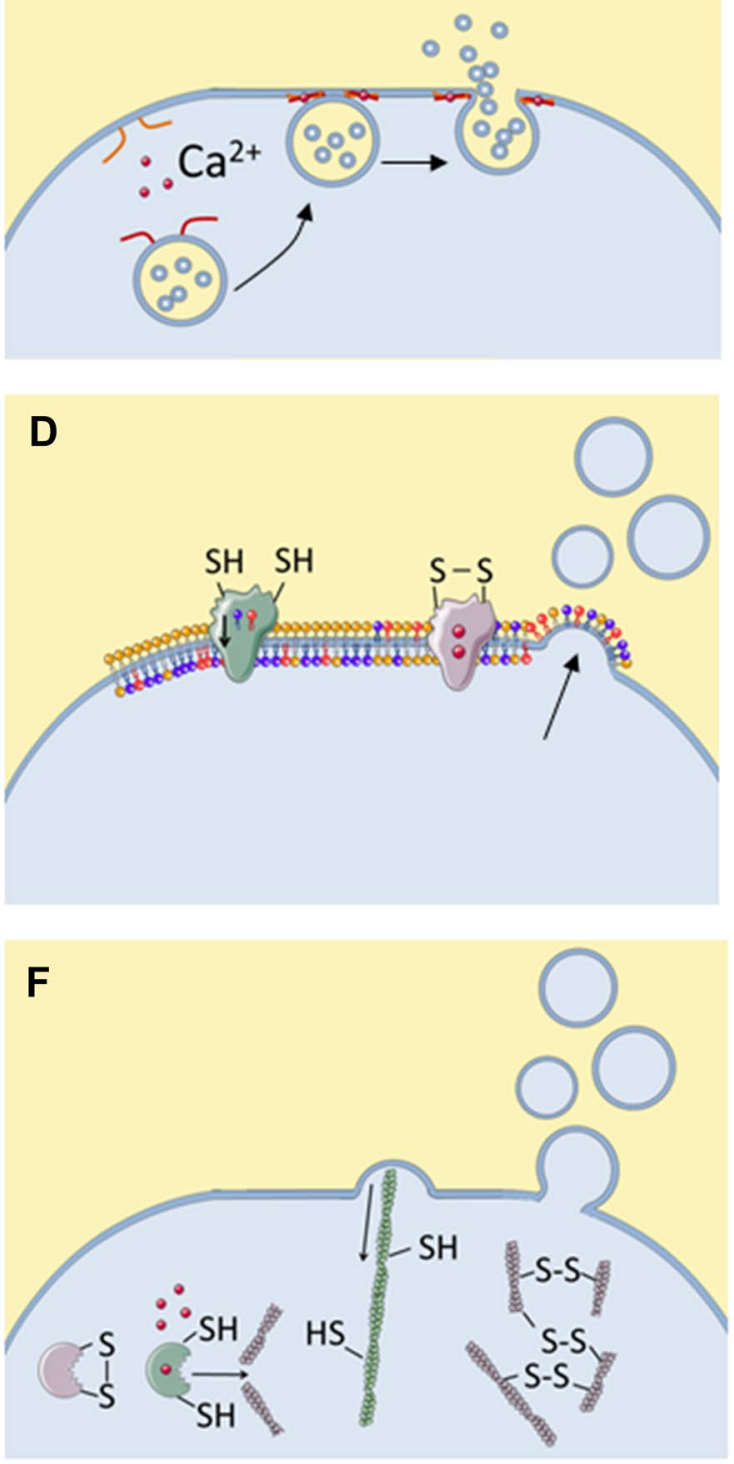

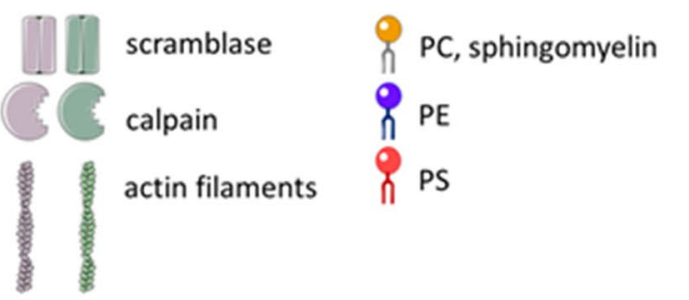

activity of syncytins depends on several highly conserved cysteine residues [88], supporting the notion that they may be subject to thiol oxidoreductase regulation.

\section{Phospholipid flippases and scramblase}

Phospholipid flippases and scramblase are enzymes that regulate the proportions of various phospholipids in the inner 
४Fig. 2 Known modulators of EV release that are directly or indirectly regulated by redox-sensitive thiols. Active proteins are represented in green and inactive proteins in purple. Disulfide bonds $(-\mathrm{S}-\mathrm{S}-)$ in this figure are used representatively for all oxidative thiol modifications. a Several calcium channels become activated upon thiol oxidation, resulting in calcium influx and increased cytoplasmic calcium concentration. b Upon the thiol-dependent calcium influx, SNAREs mediate calcium-dependent fusion of MVBs with the plasma membrane, resulting in exosome release. $\mathbf{c}$ Reduced, but not oxidize NSF catalyzes the separation of v-SNAREs and t-SNAREs, allowing their recovery for repeated membrane fusion events. d Flippases ensure localization of PE and PS in the inner membrane leaflet. Upon thiol oxidation or upon thiol-dependent calcium influx, the enzymatic activity of flippase is inhibited, resulting in accumulation of PE and PS in the outer membrane leaflet and consequently, in membrane blebbing. e Upon thiol-dependent calcium influx, scramblase becomes activated, allowing PE and PS to diffuse to the outer membrane leaflet, enhancing membrane blebbing. $f$ The actin cytoskeleton depends on reduced thiols for retracting membrane blebs. Oxidation of actin thiols causes depolymerization of actin filaments and impairs their functionality. Moreover, actin filaments can be degraded by calpains, cysteine proteases which are activated by cytoplasmic calcium but inactivated by thiol oxidation. NSF, $N$-ethylmaleimide sensitive factor; PC, phosphatidylcholine; PE, phosphatidylethanolamine; PS, phosphatidylserine SNARE, soluble NSF attachment protein receptor; t-SNARE, target membrane-associated SNARE; v-SNARE, vesicle-associated SNARE. This figure was created using Servier Medical Art

and outer leaflet of the cell membrane. Each membrane lipid has a characteristic shape due to the form of its head and the composition of its acyl tail. Therefore, the phospholipid composition of the inner and outer membrane leaflets determines membrane curvature. Under physiological conditions, phospholipid flippases assure the localization of the negatively charged phosphatidylserine (PS) and the conical phosphatidylethanolamine (PE) in the inner membrane leaflet. Importantly, flippase function depends on free thiol groups and is inhibited by thiol scavengers $[89,90]$. This results in accumulation of PE and PS in the outer membrane leaflet and, consequently, in curving of the plasma membrane into blebs (Fig. 2d). Calcium influx, for instance triggered by oxidation of thiol-bearing calcium channels, also inhibits flippase function [91]. Furthermore, it stimulates the activity of scramblase, an enzyme that allows phospholipids to move along their concentration gradient from one membrane leaflet to the other (Fig. 2e) [91]. Together, calcium-dependent flippase inhibition and scramblase activation result in rapid accumulation of PS and PE in the outer leaflet and in bleb formation. Loss of membrane asymmetry is of direct relevance for microvesicle formation. In C. elegans, deletion of the PE-flippase TAT5 resulted in PE accumulation in the outer membrane leaflet and in large scale shedding of 100-200 nm sized microvesicles from the plasma membrane [92]. Additionally, a number of studies report that ROS or RCS-induced microvesicle production is associated with cellular PS externalization, which may be caused by flippase inactivation and/or scramblase activation [40].

\section{Retractive actin filaments and calpains}

Under physiological conditions, membrane blebbing is counteracted by the retractive force of cytoskeletal actin filaments, whose activity depends on reduced thiols [93, 94] (Fig. 2e). Cytoskeletal inhibition by membrane-permeable thiol scavengers results in rapid and abundant shedding of plasma membrane-derived microvesicles (reviewed in [95]). The EVs induced by this treatment are very large $(5-15 \mu \mathrm{m}$ in diameter) and are thought to reflect the cytosolic and plasma membrane composition of their cells of origin [39, 95]. However, such large EVs rarely occur under physiological conditions. Thus, it remains to be elucidated whether blocking of cytoskeletal free thiols contributes to normal EV biogenesis. Thom et al. reported that exposure of neutrophils to $\mathrm{CO}_{2}$ results in increased activity of inducible nitric oxide synthase (iNOS) and, consequently, in S-nitrosylation of actin. Abrogation of actin S-nitrosylation by UV-light prevented the $\mathrm{EV}$ induction, suggesting that the $\mathrm{S}$-nitrosylation was required for $\mathrm{CO}_{2}$-induced $\mathrm{EV}$ release. Intriguingly, the authors found that $\mathrm{S}$-nitrosylated actin was associated with phospholipid flippase and PDI, which may further contribute to thiol-dependent regulation of EV release as discussed above.

Retraction of membrane blebs is additionally regulated by calpains, cysteine proteases that degrade actin filaments. Calcium-dependent activation of calpains prevents retraction of membrane blebs and promotes microvesicle formation $[91,96]$. However, while calpains are activated by calcium, they become inactivated when their free thiols are oxidized. Therefore, calpain-dependent microvesicle release may be enhanced by membrane impermeable thiol-reactive compounds that activate calcium influx channels at the cell surface, but inactivated by thiol-reactive compounds that enter the cell and oxidize the active site thiols of calpains. Congruently, Dachary-Prigent et al. have shown that the membrane-permeable RCS $N$-ethylmaleimide and diamide inhibit calpain function and thereby prevent the release of platelet EVs in response to the calcium ionophore A23187 [97].

\section{Cell surface-exposed thiols}

A number of recent studies have proposed that the redox state of cell surface-exposed thiols is involved in the regulation of EV release [41, 47, 52]. Firstly, Furlan-Freguia et al. have shown that stimulation of murine macrophages with the danger-associated molecular pattern (DAMP) ATP results in $\mathrm{P} 2 \mathrm{X} 7$ receptor-dependent upregulation of free thiols at the cell surface and in ROS-dependent release of thiol-rich microvesicles [52]. Cell pre-treatment with the membrane impermeable thiol-scavenger DTNB, as well as inhibition of PDI reductase activity (using the anti-PDI clone RL90) 
prevented the microvesicle induction in response to ATP [52]. In contrast, inhibition of PDI oxidase activity (using the anti-PDI clone 34) directly induced increased cell surface thiols and thiol-rich microvesicle release [52]. A possible interpretation of these findings is that PDI may maintain thiols in an oxidized state under control conditions, thereby preventing microvesicle formation. Upon ATP exposure, PDI activity may then shift from oxidase to reductase activity, resulting in the appearance of free cell surface thiols and subsequent ROS-dependent induction of thiol-rich microvesicles. Similarly to Furlan-Freguia et al., Szabó-Taylor et al. have found that stimulation of human monocytes with proinflammatory stimuli, namely lipopolysaccharide (LPS) or tumor necrosis factor (TNF)- $\alpha$, caused an upregulation of cell-surface-exposed thiols [47]. However, the EVs that these cells secreted were poor in exofacial thiols [47], in contrast to the thiol-rich EVs observed by Furlan-Freguia et al. While Szabó-Taylor et al. did not assess whether there was a quantitative change in EV release when monocytes were stimulated with LPS or TNF- $\alpha$, they did hypothesize that the shedding of thiol-poor EVs may be a protective mechanism to maintain the cell surface in a reduced state [47].

Data from our group further corroborates that the redox state of exofacial thiols regulates EV release [41], although part of our results appear to disagree with findings of the two other groups. We found that treatment of airway epithelial cells with the RCS acrolein, but not with the ROS $\mathrm{H}_{2} \mathrm{O}_{2}$ causes depletion of cell surface thiols. Acrolein as well as the membrane impermeable thiol scavengers DTNB and bacitracin triggered increased release of small EVs expressing the exosome markers CD63 and CD81, whereas $\mathrm{H}_{2} \mathrm{O}_{2}$ had no measurable effect on EV release. The EV induction appeared to be directly caused by the depletion of cell surface thiols rather than being associated with the cell's adaptive antioxidant response because EV induction required continuous presence of the RCS, whereas a transient RCSstimulation was sufficient to induce upregulation of the cellular antioxidant glutathione [41]. In our study, neither the anti-PDI clone RL90 nor the PDI-inhibitor rutin affected basal or RCS-induced EV release. Although we were unable to identify a specific exofacial target protein of thiol modifications, we could conclude that depletion of cell surface thiols is sufficient to elicit an increased EV release in airway epithelial cells.

Although all three studies provide evidence that cell surface thiols may be crucially involved in the regulation of EV release, a number of discrepancies remain. While Furlan-Freguia et al. argue that an increase in the number of cell-surface thiols is required for EV induction [52], we found that depletion of exofacial thiols enhances EV release [41]. Another discrepancy is that EVs released by cells with increased cell-surface thiols were rich in exofacial thiols in the study of Furlan-Freguia et al. [52], while they were poor in exofacial thiols in the study of Szabó-Taylor et al. [47]. Additional research is required to reveal whether the differences between studies are due to the stimuli, the cell types, the EV subpopulations or the exposure times that were investigated. It has to be noted that oxidative processes were involved in the cell surface thiol-dependent EV release in all three studies. Thus, initial upregulation of reduced cell surface thiols may be a prerequisite for subsequent oxidantdependent thiol modifications and EV induction. It should be investigated whether the amount of cell surface thiols regulates EV release via one or more specific thiol-bearing proteins, or whether a more general mechanism is involved, such as disulfide cross-linking of exofacial thiol-bearing proteins by ROS or formation of bulky adducts by RCS, both of which may influence membrane curvature.

\section{Thiol protection to prevent EV modifications: therapeutic implications}

As thiol modifications appear to modulate the formation and functions of EVs upon cell exposure to pro-oxidant conditions, thiol protection may be a promising strategy to prevent detrimental changes in EV signaling under such conditions. Indeed, several thiol-bearing small molecules, such as NAC; NACA and glutathione are able to prevent EV induction by a variety of ROS, RCS and pro-inflammatory stimuli, likely by scavenging thiol-reactive compounds and preventing them from reacting with cellular thiols [41-43, 52, 53, 98-100]. NAC also inhibits EV-associated release of TF and PS by cells exposed to oxidant conditions and consequently decreases the procoagulant potential of EVs [42, 52, 53]. It may also prevent EV-dependent secretion of pro-inflammatory molecules [98], although this has been less well studied. Importantly, NAC treatment appears to restore EV secretion, composition and functions to the level observed for unexposed cells, rather than completely inhibiting EV signaling. Thus, NAC may specifically prevent oxidant-induced detrimental changes in EV signaling without interfering with the physiological functions of EVs.

In lung disease, particularly chronic obstructive pulmonary disease (COPD), NAC is currently used as a mucolytic. According to recent meta-analyses, NAC is associated with improved small airway function and decreased exacerbation frequency in this target group when administered orally at $\geq 1200 \mathrm{mg} /$ day [101-103]. Importantly, it has been proposed that these clinical benefits can at least partly be attributed to antioxidant and anti-inflammatory properties of NAC or its thiol-bearing metabolites rather than to the mucolytic activity alone [102, 104]. Additional research could reveal whether prevention of cellular thiol modifications and subsequent changes in EV signaling contribute to this alternative mechanism of 
action. Importantly, NAC has recently been proposed to be of clinical benefit in other conditions that are also hallmarked by inflammation and oxidative stress, such as insulin resistance and possibly neurological disorders [105, 106]. There is even early stage evidence suggesting an anti-thrombotic effect of NAC treatment [104, 107, 108]. This is in line with the observation that NAC prevents the release of procoagulant $\mathrm{EV} s$ in the response to oxidative thiol modifications $[42,52,53]$. Translational studies are required to elucidate whether inhibition of thiol-dependent EV modifications contributes to the clinical benefit of NAC in COPD patients and to determine whether additional target groups may benefit from NAC treatment due to this mechanism of action.

\section{Conclusion}

Taken together, protein thiols play a crucial role in the modulation of membrane fusion and membrane blebbing. Thereby, they regulate EV release and, possibly, uptake. EV release under thiol-depleting conditions may have evolved as a beneficial adaptive response to cellular oxidative stress. However, these EVs may also exert detrimental pro-inflammatory and prothrombotic effects. Additional research is required to establish the importance of thiols in EV biology and to identify the molecular mechanisms that mediate the thiol-dependent regulation of EV-related membrane rearrangements. Many known inhibitors of EV signaling interfere with vital cellular processes, making them unsuitable for the therapeutic modulation of EV signaling. Thiolcontaining antioxidants such as NAC counteract the induction of EVs by pro-oxidant stimuli in vitro. Clinical studies are required to investigate whether inhibiting the release of pro-inflammatory and procoagulant EVs contributes to the therapeutic benefit of NAC in conditions of chronic inflammation and oxidative stress. Additionally, future research should focus on identifying the specific thiol-dependent mechanisms that are involved in the regulation of EV release and uptake, as these may be promising targets for specific pharmacological modulation of EV signaling.

\section{Compliance with ethical standards}

Conflict of interest The authors declare no conflict of interest.

Funding This work was supported by the Netherlands Organization for Scientific Research (NWO) Grant 022.003.011 with the title "NUTRIM NWO Graduate Program: Metabolism and chronic disease" awarded to BJB.

Open Access This article is distributed under the terms of the Creative Commons Attribution 4.0 International License (http://creativeco mmons.org/licenses/by/4.0/), which permits unrestricted use, distribution, and reproduction in any medium, provided you give appropriate credit to the original author(s) and the source, provide a link to the Creative Commons license, and indicate if changes were made.

\section{References}

1. Wolf $P$ (1967) The nature and significance of platelet products in human plasma. Br J Haematol 13(3):269-288

2. Pisitkun T, Shen RF, Knepper MA (2004) Identification and proteomic profiling of exosomes in human urine. Proc Natl Acad Sci USA 101(36):13368-13373. https://doi.org/10.1073/pnas.04034 53101

3. Admyre C, Grunewald J, Thyberg J, Gripenback S, Tornling G, Eklund A, Scheynius A, Gabrielsson S (2003) Exosomes with major histocompatibility complex class II and co-stimulatory molecules are present in human BAL fluid. Eur Respir J 22(4):578-583

4. Choi DS, Kim DK, Kim YK, Gho YS (2013) Proteomics, transcriptomics and lipidomics of exosomes and ectosomes. Proteomics 13(10-11):1554-1571. https://doi.org/10.1002/ pmic.201200329

5. Yanez-Mo M, Siljander PR, Andreu Z, Zavec AB, Borras FE, Buzas EI, Buzas K, Casal E, Cappello F, Carvalho J, Colas E, Cordeiro-da Silva A, Fais S, Falcon-Perez JM, Ghobrial IM, Giebel B, Gimona M, Graner M, Gursel I, Gursel M, Heegaard NH, Hendrix A, Kierulf P, Kokubun K, Kosanovic M, Kralj-Iglic V, Kramer-Albers EM, Laitinen S, Lasser C, Lener T, Ligeti E, Line A, Lipps G, Llorente A, Lotvall J, Mancek-Keber M, Marcilla A, Mittelbrunn M, Nazarenko I, Nolte-'t Hoen EN, Nyman TA, O’Driscoll L, Olivan M, Oliveira C, Pallinger E, Del Portillo HA, Reventos J, Rigau M, Rohde E, Sammar M, Sanchez-Madrid F, Santarem N, Schallmoser K, Ostenfeld MS, Stoorvogel W, Stukelj R, Van der Grein SG, Vasconcelos MH, Wauben MH, De Wever O (2015) Biological properties of extracellular vesicles and their physiological functions. J Extracell Vesicles 4:27066. https://doi.org/10.3402/jev.v4.27066

6. Raposo G, Stoorvogel W (2013) Extracellular vesicles: exosomes, microvesicles, and friends. J Cell Biol 200(4):373383. https://doi.org/10.1083/jcb.201211138

7. Kowal J, Arras G, Colombo M, Jouve M, Morath JP, PrimdalBengtson B, Dingli F, Loew D, Tkach M, Thery C (2016) Proteomic comparison defines novel markers to characterize heterogeneous populations of extracellular vesicle subtypes. Proc Natl Acad Sci USA 113(8):E968-E977. https://doi.org/10.1073/ pnas. 1521230113

8. Abels ER, Breakefield XO (2016) Introduction to extracellular vesicles: biogenesis, RNA cargo selection, content, release, and uptake. Cell Mol Neurobiol 36(3):301-312. https://doi. org/10.1007/s10571-016-0366-z

9. Dreyer F, Baur A (2016) Biogenesis and functions of exosomes and extracellular vesicles. Methods Mol Biol 1448:201-216. https://doi.org/10.1007/978-1-4939-3753-0_15

10. Hessvik NP, Llorente A (2018) Current knowledge on exosome biogenesis and release. Cell Mol Life Sci: CMLS 75(2):193-208. https://doi.org/10.1007/s00018-017-2595-9

11. Mulcahy LA, Pink RC, Carter DR (2014) Routes and mechanisms of extracellular vesicle uptake. J Extracell Vesicles. https ://doi.org/10.3402/jev.v3.24641

12. Prada I, Meldolesi J (2016) Binding and fusion of extracellular vesicles to the plasma membrane of their cell targets. Int J Mol Sci. https://doi.org/10.3390/ijms 17081296

13. Robbins PD (2017) Extracellular vesicles and aging. Stem cell investigation 4:98. https://doi.org/10.21037/sci.2017.12.03 
14. Minciacchi VR, Freeman MR, Di Vizio D (2015) Extracellular vesicles in cancer: exosomes, microvesicles and the emerging role of large oncosomes. Semin Cell Dev Biol 40:41-51. https:// doi.org/10.1016/j.semcdb.2015.02.010

15. Loyer X, Vion AC, Tedgui A, Boulanger CM (2014) Microvesicles as cell-cell messengers in cardiovascular diseases. Circ Res 114(2):345-353. https://doi.org/10.1161/CIRCRESAHA .113 .300858

16. Fujita Y, Kosaka N, Araya J, Kuwano K, Ochiya T (2015) Extracellular vesicles in lung microenvironment and pathogenesis. Trends in molecular medicine 21(9):533-542. https://doi. org/10.1016/j.molmed.2015.07.004

17. Ayers L, Nieuwland R, Kohler M, Kraenkel N, Ferry B, Leeson $P$ (2015) Dynamic microvesicle release and clearance within the cardiovascular system: triggers and mechanisms. Clin Sci 129(11):915-931. https://doi.org/10.1042/CS20140623

18. Larson MC, Hillery CA, Hogg N (2014) Circulating membrane-derived microvesicles in redox biology. Free Radic Biol Med 73:214-228. https://doi.org/10.1016/j.freeradbio med.2014.04.017

19. Strulovici-Barel Y, Staudt MR, Krause A, Gordon C, Tilley AE, Harvey BG, Kaner RJ, Hollmann C, Mezey JG, Bitter H, Pillai SG, Hilton H, Wolff G, Stevenson CS, Visvanathan S, Fine JS, Crystal RG (2016) Persistence of circulating endothelial microparticles in COPD despite smoking cessation. Thorax 71(12):1137-1144. https://doi.org/10.1136/thoraxjnl-2015208274

20. Lakhter AJ, Sims EK (2015) Minireview: emerging roles for extracellular vesicles in diabetes and related metabolic disorders. Mol Endocrinol 29(11):1535-1548. https://doi.org/10.1210/ me.2015-1206

21. Ostrowski M, Carmo NB, Krumeich S, Fanget I, Raposo G, Savina A, Moita CF, Schauer K, Hume AN, Freitas RP, Goud B, Benaroch P, Hacohen N, Fukuda M, Desnos C, Seabra MC, Darchen F, Amigorena S, Moita LF, Thery C (2010) Rab27a and Rab27b control different steps of the exosome secretion pathway. Nat Cell Biol 12(1):19-30, sup pp 11-13. https://doi.org/10.1038/ ncb2000

22. Trajkovic K, Hsu C, Chiantia S, Rajendran L, Wenzel D, Wieland F, Schwille P, Brugger B, Simons M (2008) Ceramide triggers budding of exosome vesicles into multivesicular endosomes. Science 319(5867):1244-1247. https://doi.org/10.1126/scien ce. 1153124

23. Kimura T, Niki I (2011) Rab27a in pancreatic beta-cells, a busy protein in membrane trafficking. Prog Biophys Mol Biol 107(2):219-223. https://doi.org/10.1016/j.pbiomolbio .2011 .06 .016

24. Shamseddine AA, Airola MV, Hannun YA (2015) Roles and regulation of neutral sphingomyelinase-2 in cellular and pathological processes. Adv Biol Regul 57:24-41. https://doi. org/10.1016/j.jbior.2014.10.002

25. Winterbourn CC, Hampton MB (2008) Thiol chemistry and specificity in redox signaling. Free Radic Biol Med 45(5):549-561. https://doi.org/10.1016/j.freeradbiomed.2008.05.004

26. Antelmann H, Helmann JD (2011) Thiol-based redox switches and gene regulation. Antioxid Redox Signal 14(6):1049-1063. https://doi.org/10.1089/ars.2010.3400

27. Poole LB (2015) The basics of thiols and cysteines in redox biology and chemistry. Free Radic Biol Med 80:148-157. https://doi. org/10.1016/j.freeradbiomed.2014.11.013

28. Marino SM, Gladyshev VN (2010) Cysteine function governs its conservation and degeneration and restricts its utilization on protein surfaces. J Mol Biol 404(5):902-916. https://doi. org/10.1016/j.jmb.2010.09.027

29. Sanders DA (2000) Sulfhydryl involvement in fusion mechanisms. Sub-Cell Biochem 34:483-514
30. Horinouchi T, Higashi T, Mazaki Y, Miwa S (2016) Carbonyl compounds in the gas phase of cigarette mainstream smoke and their pharmacological properties. Biol Pharm Bull 39(6):909914. https://doi.org/10.1248/bpb.b16-00025

31. Valavanidis A, Vlachogianni T, Fiotakis K (2009) Tobacco smoke: involvement of reactive oxygen species and stable free radicals in mechanisms of oxidative damage, carcinogenesis and synergistic effects with other respirable particles. Int J Environ Res Public Health 6(2):445-462. https://doi.org/10.3390/ijerp h6020445

32. Jakober CA, Robert MA, Riddle SG, Destaillats H, Charles MJ, Green PG, Kleeman MJ (2008) Carbonyl emissions from gasoline and diesel motor vehicles. Environ Sci Technol 42(13):4697-4703

33. Wen X, Wu J, Wang F, Liu B, Huang C, Wei Y (2013) Deconvoluting the role of reactive oxygen species and autophagy in human diseases. Free Radic Biol Med 65:402-410. https://doi. org/10.1016/j.freeradbiomed.2013.07.013

34. Bein K, Leikauf GD (2011) Acrolein - a pulmonary hazard. Mol Nutr Food Res 55(9):1342-1360. https://doi.org/10.1002/ mnfr.201100279

35. Mano J (2012) Reactive carbonyl species: their production from lipid peroxides, action in environmental stress, and the detoxification mechanism. Plant Physiol Biochem: PPB/Societe francaise de physiologie vegetale 59:90-97. https://doi.org/10.1016/j. plaphy.2012.03.010

36. Couto N, Wood J, Barber J (2016) The role of glutathione reductase and related enzymes on cellular redox homoeostasis network. Free Radic Biol Med 95:27-42. https://doi.org/10.1016/j. freeradbiomed.2016.02.028

37. Randall MJ, Hristova M, van der Vliet A (2013) Protein alkylation by the alpha, beta-unsaturated aldehyde acrolein. A reversible mechanism of electrophile signaling? FEBS Lett 587(23):3808-3814. https://doi.org/10.1016/j.febs1 et.2013.10.006

38. Belkin M, Hardy WG (1961) Relation between water permeability and integrity of sulfhydryl groups in malignant and normal cells. J Biophys Biochem Cytol 9(4):733-745

39. Scott RE, Perkins RG, Zschunke MA, Hoerl BJ, Maercklein PB (1979) Plasma membrane vesiculation in 3T3 and SV3T3 cells. I. Morphological and biochemical characterization. J Cell Sci 35:229-243

40. Vatsyayan R, Kothari H, Pendurthi UR, Rao LV (2013) 4-Hydroxy-2-nonenal enhances tissue factor activity in human monocytic cells via p38 mitogen-activated protein kinase activation-dependent phosphatidylserine exposure. Arterioscler Thromb Vasc Biol 33(7):1601-1611. https://doi.org/10.1161/ ATVBAHA.113.300972

41. Benedikter BJ, Volgers C, van Eijck PH, Wouters EF, Savelkoul PH, Reynaert NL, Haenen GR, Rohde GG, Weseler AR, Stassen FR (2017) Cigarette smoke extract induced exosome release is mediated by depletion of exofacial thiols and can be inhibited by thiol-antioxidants. Free Radic Biol Med. https://doi. org/10.1016/j.freeradbiomed.2017.03.026

42. Novelli F, Neri T, Tavanti L, Armani C, Noce C, Falaschi F, Bartoli ML, Martino F, Palla A, Celi A, Paggiaro P (2014) Procoagulant, tissue factor-bearing microparticles in bronchoalveolar lavage of interstitial lung disease patients: an observational study. PLoS One 9(4):e95013. https://doi.org/10.1371/journ al.pone.0095013

43. Carver KA, Yang D (2016) $N$-acetylcysteine amide protects against oxidative stress-induced microparticle release from human retinal pigment epithelial cells. Invest Ophthalmol Vis Sci 57(2):360-371. https://doi.org/10.1167/iovs.15-17117

44. Nolan S, Dixon R, Norman K, Hellewell P, Ridger V (2008) Nitric oxide regulates neutrophil migration through microparticle 
formation. Am J Pathol 172(1):265-273. https://doi.org/10.2353/ ajpath.2008.070069

45. Ju R, Zhuang ZW, Zhang J, Lanahan AA, Kyriakides T, Sessa WC, Simons M (2014) Angiopoietin-2 secretion by endothelial cell exosomes: regulation by the phosphatidylinositol 3-kinase (PI3K)/Akt/endothelial nitric oxide synthase (eNOS) and syndecan-4/syntenin pathways. J Biol Chem 289(1):510-519. https://doi.org/10.1074/jbc.M113.506899

46. Szabo-Taylor K, Ryan B, Osteikoetxea X, Szabo TG, Sodar B, Holub M, Nemeth A, Paloczi K, Pallinger E, Winyard P, Buzas EI (2015) Oxidative and other posttranslational modifications in extracellular vesicle biology. Semin Cell Dev Biol 40:8-16. https://doi.org/10.1016/j.semcdb.2015.02.012

47. Szabo-Taylor KE, Toth EA, Balogh AM, Sodar BW, Kadar L, Paloczi K, Fekete N, Nemeth A, Osteikoetxea X, Vukman KV, Holub M, Pallinger E, Nagy G, Winyard PG, Buzas EI (2017) Monocyte activation drives preservation of membrane thiols by promoting release of oxidised membrane moieties via extracellular vesicles. Free Radic Biol Med 108:56-65. https ://doi.org/10.1016/j.freeradbiomed.2017.03.016

48. Reisz JA, Wither MJ, Dzieciatkowska M, Nemkov T, Issaian A, Yoshida T, Dunham AJ, Hill RC, Hansen KC, D'Alessandro A (2016) Oxidative modifications of glyceraldehyde 3-phosphate dehydrogenase regulate metabolic reprogramming of stored red blood cells. Blood 128(12):e32-e42. https://doi.org/10.1182/ blood-2016-05-714816

49. Binder CJ, Papac-Milicevic N, Witztum JL (2016) Innate sensing of oxidation-specific epitopes in health and disease. Nat Rev Immunol 16(8):485-497. https://doi.org/10.1038/ nri.2016.63

50. Li M, Yu D, Williams KJ, Liu ML (2010) Tobacco smoke induces the generation of procoagulant microvesicles from human monocytes/macrophages. Arterioscler Thromb Vasc Biol 30(9):18181824. https://doi.org/10.1161/ATVBAHA.110.209577

51. Woei AJFJ, De Kruif MD, Garcia Rodriguez P, Osanto S, Bertina RM (2012) Microparticles expressing tissue factor are concurrently released with markers of inflammation and coagulation during human endotoxemia. $\mathrm{J}$ Thromb Haemost: JTH 10(6):1185-1188. https://doi.org/10.111 1/j.1538-7836.2012.04733.x

52. Furlan-Freguia C, Marchese P, Gruber A, Ruggeri ZM, Ruf W (2011) P2X7 receptor signaling contributes to tissue factordependent thrombosis in mice. J Clin Investig 121(7):2932-2944. https://doi.org/10.1172/JCI46129

53. Lim KM, Kim S, Noh JY, Kim K, Jang WH, Bae ON, Chung SM, Chung JH (2010) Low-level mercury can enhance procoagulant activity of erythrocytes: a new contributing factor for mercury-related thrombotic disease. Environ Health Perspect 118(7):928-935. https://doi.org/10.1289/ehp.0901473

54. Owens AP 3rd, Mackman N (2011) Microparticles in hemostasis and thrombosis. Circ Res 108(10):1284-1297. https://doi. org/10.1161/CIRCRESAHA.110.233056

55. Kastelowitz N, Yin H (2014) Exosomes and microvesicles: identification and targeting by particle size and lipid chemical probes. Chembiochem: A Eur J Chem Biol 15(7):923-928. https://doi. org/10.1002/cbic.201400043

56. Kleinjan A, Boing AN, Sturk A, Nieuwland R (2012) Microparticles in vascular disorders: how tissue factor-exposing vesicles contribute to pathology and physiology. Thromb Res 130(Suppl 1):S71-S73. https://doi.org/10.1016/j.thromres.2012.08.281

57. Ahamed J, Versteeg HH, Kerver M, Chen VM, Mueller BM, Hogg PJ, Ruf W (2006) Disulfide isomerization switches tissue factor from coagulation to cell signaling. Proc Natl Acad Sci USA 103(38):13932-13937. https://doi.org/10.1073/pnas.06064 11103
58. Bucki R, Bachelot-Loza C, Zachowski A, Giraud F, Sulpice JC (1998) Calcium induces phospholipid redistribution and microvesicle release in human erythrocyte membranes by independent pathways. Biochemistry 37(44):15383-15391. https:// doi.org/10.1021/bi9805238

59. Savina A, Furlan M, Vidal M, Colombo MI (2003) Exosome release is regulated by a calcium-dependent mechanism in K562 cells. J Biol Chem 278(22):20083-20090. https://doi. org/10.1074/jbc.M301642200

60. Zima AV, Blatter LA (2006) Redox regulation of cardiac calcium channels and transporters. Cardiovasc Res 71(2):310-321. https ://doi.org/10.1016/j.cardiores.2006.02.019

61. Mori Y, Takahashi N, Polat OK, Kurokawa T, Takeda N, Inoue M (2016) Redox-sensitive transient receptor potential channels in oxygen sensing and adaptation. Pflugers Arch 468(1):85-97. https://doi.org/10.1007/s00424-015-1716-2

62. Muralidharan P, Cserne Szappanos H, Ingley E, Hool L (2016) Evidence for redox sensing by a human cardiac calcium channel. Sci Rep 6:19067. https://doi.org/10.1038/srep19067

63. Kichko TI, Kobal G, Reeh PW (2015) Cigarette smoke has sensory effects through nicotinic and TRPA1 but not TRPV1 receptors on the isolated mouse trachea and larynx. Am J Physiol Lung Cell Mol Physiol 309(8):L812-L820. https://doi.org/10.1152/ ajplung.00164.2015

64. Todorovic SM, Jevtovic-Todorovic V (2014) Redox regulation of neuronal voltage-gated calcium channels. Antioxid Redox Signal 21(6):880-891. https://doi.org/10.1089/ars.2013.5610

65. Zygmunt PM, Hogestatt ED (2014) Trpa1. Handb Exp Pharmacol 222:583-630. https://doi.org/10.1007/978-3-642-54215-2_23

66. Hinman A, Chuang HH, Bautista DM, Julius D (2006) TRP channel activation by reversible covalent modification. Proc Natl Acad Sci USA 103(51):19564-19568. https://doi.org/10.1073/ pnas.0609598103

67. Thom SR, Bhopale VM, Hu J, Yang M (2017) Increased carbon dioxide levels stimulate neutrophils to produce microparticles and activate the nucleotide-binding domain-like receptor 3 inflammasome. Free Radic Biol Med 106:406-416. https://doi. org/10.1016/j.freeradbiomed.2017.03.005

68. Beckers CJ, Block MR, Glick BS, Rothman JE, Balch WE (1989) Vesicular transport between the endoplasmic reticulum and the Golgi stack requires the NEM-sensitive fusion protein. Nature 339(6223):397-398. https://doi.org/10.1038/339397a0

69. Fader CM, Sanchez DG, Mestre MB, Colombo MI (2009) TIVAMP/VAMP7 and VAMP3/cellubrevin: two v-SNARE proteins involved in specific steps of the autophagy/multivesicular body pathways. Biochem Biophys Acta 1793(12):1901-1916. https:// doi.org/10.1016/j.bbamcr.2009.09.011

70. Robinson LJ, Aniento F, Gruenberg J (1997) NSF is required for transport from early to late endosomes. J Cell Sci $110(\mathrm{Pt}$ 17):2079-2087

71. Bombardier JP, Munson M (2015) Three steps forward, two steps back: mechanistic insights into the assembly and disassembly of the SNARE complex. Curr Opin Chem Biol 29:66-71. https:// doi.org/10.1016/j.cbpa.2015.10.003

72. Zhao M, Brunger AT (2016) Recent advances in deciphering the structure and molecular mechanism of the AAA + ATPase $\mathrm{N}$-ethylmaleimide-sensitive factor (NSF). J Mol Biol 428(9 Pt B):1912-1926. https://doi.org/10.1016/j.jmb.2015.10.026

73. Hyenne V, Apaydin A, Rodriguez D, Spiegelhalter C, HoffYoessle S, Diem M, Tak S, Lefebvre O, Schwab Y, Goetz JG, Labouesse M (2015) RAL-1 controls multivesicular body biogenesis and exosome secretion. The Journal of cell biology 211(1):27-37. https://doi.org/10.1083/jcb.201504136

74. Gross JC, Chaudhary V, Bartscherer K, Boutros M (2012) Active Wnt proteins are secreted on exosomes. Nat Cell Biol 14(10):1036-1045. https://doi.org/10.1038/ncb2574 
75. Parakh S, Atkin JD (2015) Novel roles for protein disulphide isomerase in disease states: a double edged sword? Front Cell Dev Biol 3:30. https://doi.org/10.3389/fcell.2015.00030

76. Benham AM (2012) The protein disulfide isomerase family: key players in health and disease. Antioxid Redox Signal 16(8):781789. https://doi.org/10.1089/ars.2011.4439

77. Donoghue N, Yam PT, Jiang XM, Hogg PJ (2000) Presence of closely spaced protein thiols on the surface of mammalian cells. Protein Sci 9(12):2436-2445. https://doi.org/10.1110/ ps.9.12.2436

78. Booth C, Koch GL (1989) Perturbation of cellular calcium induces secretion of luminal ER proteins. Cell 59(4):729-737

79. Raturi A, Miersch S, Hudson JW, Mutus B (2008) Platelet microparticle-associated protein disulfide isomerase promotes platelet aggregation and inactivates insulin. Biochem Biophys Acta 1778(12):2790-2796. https://doi.org/10.1016/j.bbame m.2008.07.003

80. Mammoto A, Masumoto N, Tahara M, Yoneda M, Nishizaki T, Tasaka K, Miyake A (1997) Involvement of a sperm protein sensitive to sulfhydryl-depleting reagents in mouse sperm-egg fusion. J Exp Zool 278(3):178-188

81. Ellerman DA, Myles DG, Primakoff P (2006) A role for sperm surface protein disulfide isomerase activity in gamete fusion: evidence for the participation of ERp57. Dev Cell 10(6):831-837. https://doi.org/10.1016/j.devcel.2006.03.011

82. Anifandis G, Messini C, Dafopoulos K, Sotiriou S, Messinis I (2014) Molecular and cellular mechanisms of sperm-oocyte interactions opinions relative to in vitro fertilization (IVF). Int $\mathbf{J}$ Mol Sci 15(7):12972-12997. https://doi.org/10.3390/ijms150712 972

83. Diwaker D, Mishra KP, Ganju L (2013) Potential roles of protein disulphide isomerase in viral infections. Acta Virol 57(3):293-304

84. Izquierdo-Useros N, Puertas MC, Borras FE, Blanco J, Martinez-Picado J (2011) Exosomes and retroviruses: the chicken or the egg? Cell Microbiol 13(1):10-17. https://doi.org/10.111 1/j.1462-5822.2010.01542.x

85. Barbouche R, Miquelis R, Jones IM, Fenouillet E (2003) Proteindisulfide isomerase-mediated reduction of two disulfide bonds of HIV envelope glycoprotein 120 occurs post-CXCR4 binding and is required for fusion. J Biol Chem 278(5):3131-3136. https:// doi.org/10.1074/jbc.M205467200

86. Markovic I, Stantchev TS, Fields KH, Tiffany LJ, Tomic M, Weiss CD, Broder CC, Strebel K, Clouse KA (2004) Thiol/ disulfide exchange is a prerequisite for CXCR4-tropic HIV-1 envelope-mediated T-cell fusion during viral entry. Blood 103(5):1586-1594. https://doi.org/10.1182/blood-2003-05-1390

87. Vargas A, Zhou S, Ethier-Chiasson M, Flipo D, Lafond J, Gilbert C, Barbeau B (2014) Syncytin proteins incorporated in placenta exosomes are important for cell uptake and show variation in abundance in serum exosomes from patients with preeclampsia. FASEB J 28(8):3703-3719. https://doi.org/10.1096/fj.13-23905 3

88. Cheynet V, Ruggieri A, Oriol G, Blond JL, Boson B, Vachot L, Verrier B, Cosset FL, Mallet F (2005) Synthesis, assembly, and processing of the Env ERVWE1/syncytin human endogenous retroviral envelope. J Virol 79(9):5585-5593. https://doi. org/10.1128/JVI.79.9.5585-5593.2005

89. Chang QL, Gummadi SN, Menon AK (2004) Chemical modification identifies two populations of glycerophospholipid flippase in rat liver ER. Biochemistry 43(33):10710-10718. https://doi. org/10.1021/bi049063a

90. Moriyama Y, Nelson N (1988) Purification and properties of a vanadate- and $N$-ethylmaleimide-sensitive ATPase from chromaffin granule membranes. J Biol Chem 263(17):8521-8527
91. Morel O, Jesel L, Freyssinet JM, Toti F (2011) Cellular mechanisms underlying the formation of circulating microparticles. Arterioscler Thromb Vasc Biol 31(1):15-26. https://doi. org/10.1161/ATVBAHA.109.200956

92. Wehman AM, Poggioli C, Schweinsberg P, Grant BD, Nance J (2011) The P4-ATPase TAT-5 inhibits the budding of extracellular vesicles in C. elegans embryos. Curr Biol: CB 21(23):19511959. https://doi.org/10.1016/j.cub.2011.10.040

93. Charras GT, Hu CK, Coughlin M, Mitchison TJ (2006) Reassembly of contractile actin cortex in cell blebs. J Cell Biol 175(3):477-490. https://doi.org/10.1083/jcb.200602085

94. Dalle-Donne I, Rossi R, Milzani A, Di Simplicio P, Colombo R (2001) The actin cytoskeleton response to oxidants: from small heat shock protein phosphorylation to changes in the redox state of actin itself. Free Radic Biol Med 31(12):1624-1632

95. Ingato D, Lee JU, Sim SJ, Kwon YJ (2016) Good things come in small packages: overcoming challenges to harness extracellular vesicles for therapeutic delivery. J Control Release 241:174-185. https://doi.org/10.1016/j.jconrel.2016.09.016

96. Pasquet JM, Dachary-Prigent J, Nurden AT (1996) Calcium influx is a determining factor of calpain activation and microparticle formation in platelets. Eur J Biochem 239(3):647-654

97. Dachary-Prigent J, Freyssinet JM, Pasquet JM, Carron JC, Nurden AT (1993) Annexin V as a probe of aminophospholipid exposure and platelet membrane vesiculation: a flow cytometry study showing a role for free sulfhydryl groups. Blood 81(10):2554-2565

98. Cho YE, Im EJ, Moon PG, Mezey E, Song BJ, Baek MC (2017) Increased liver-specific proteins in circulating extracellular vesicles as potential biomarkers for drug- and alcohol-induced liver injury. PLoS One 12(2):e0172463. https://doi.org/10.1371/journ al.pone. 0172463

99. Shiau JY, Chang YQ, Nakagawa-Goto K, Lee KH, Shyur LF (2017) Phytoagent deoxyelephantopin and its derivative inhibit triple negative breast cancer cell activity through ROS-mediated exosomal activity and protein functions. Front Pharmacol 8:398. https://doi.org/10.3389/fphar.2017.00398

100. Volgers C, Benedikter BJ, Grauls GE, Hellebrand PHM, Savelkoul PHM, Stassen FRM (2017) Effects of $N$-acetyl-L-cysteine on the membrane vesicle release and growth of respiratory pathogens. FEMS Microbiol Lett. https://doi.org/10.1093/femsle/ fnx087

101. Cazzola M, Calzetta L, Page C, Jardim J, Chuchalin AG, Rogliani P, Matera MG (2015) Influence of $N$-acetylcysteine on chronic bronchitis or COPD exacerbations: a meta-analysis. Eur Respir Rev 24(137):451-461. https://doi.org/10.1183/16000617.00002 215

102. Tse HN, Tseng CZS (2014) Update on the pathological processes, molecular biology, and clinical utility of $\mathrm{N}$-acetylcysteine in chronic obstructive pulmonary disease. Int J Chronic Obstr Pulm Dis 9:825-836. https://doi.org/10.2147/Copd.S51057

103. Shen YF, Cai WR, Lei S, Zhang ZH (2014) Effect of high/low dose $\mathrm{N}$-acetylcysteine on chronic obstructive pulmonary disease: a systematic review and meta-analysis. COPD_J Chronic Obstr Pulm Dis 11(3):351-358. https://doi.org/10.3109/15412 555.2013.858315

104. Rushworth GF, Megson IL (2014) Existing and potential therapeutic uses for $\mathrm{N}$-acetylcysteine: the need for conversion to intracellular glutathione for antioxidant benefits. Pharmacol Ther 141(2):150-159. https://doi.org/10.1016/j.pharmthera 2013.09.006

105. Lasram MM, Dhouib IB, Annabi A, El Fazaa S, Gharbi N (2015) A review on the possible molecular mechanism of action of $\mathrm{N}$-acetylcysteine against insulin resistance and type- 2 diabetes 
development. Clin Biochem 48(16-17):1200-1208. https://doi. org/10.1016/j.clinbiochem.2015.04.017

106. Deepmala Slattery J, Kumar N, Delhey L, Berk M, Dean O, Spielholz C, Frye R (2015) Clinical trials of $N$-acetylcysteine in psychiatry and neurology: a systematic review. Neurosci Biobehav Rev 55:294-321. https://doi.org/10.1016/j.neubi orev.2015.04.015

107. Pawlak R, Chabielska E, Matys T, Kucharewicz I, Rolkowski R, Buczko W (2000) Thiol repletion prevents venous thrombosis in rats by nitric oxide/prostacyclin-dependent mechanism: relation to the antithrombotic action of captopril. J Cardiovasc Pharmacol 36(4):503-509
108. Lopez-Pedrera C, Barbarroja N, Jimenez-Gomez Y, CollantesEstevez E, Aguirre MA, Cuadrado MJ (2016) Oxidative stress in the pathogenesis of atherothrombosis associated with antiphospholipid syndrome and systemic lupus erythematosus: new therapeutic approaches. Rheumatology 55(12):2096-2108. https ://doi.org/10.1093/rheumatology/kew054

109. Sapir A, Avinoam O, Podbilewicz B, Chernomordik LV (2008) Viral and developmental cell fusion mechanisms: conservation and divergence. Dev Cell 14(1):11-21. https://doi.org/10.1016/j. devcel.2007.12.008 